\title{
Structure and properties of babbit Sn11Sb5,5Cu subjected to high pressure torsion
}

\author{
I.Sh. Valeev ${ }^{\dagger}$, A.Kh. Valeeva, R.R. Mulyukov, R.Kh. Khisamov \\ †valeevs@mail.ru
}

Institute for Metals Superplasticity Problems of RAS, Khalturina 39 str., 450001, Ufa, Russia

Babbitt alloys are traditionally used as a material for sliding bearings of large-sized units. The structure of babbit $\mathrm{Sn} 11 \mathrm{Sb} 5,5 \mathrm{Cu}$ consists of three phases: $\alpha$-phase, which is a solid solution of antimony and copper in the tin, $\beta$-phase is a SnSb crystal with hexagonal and rhombohedral lattice and small $\eta$-phase $\left(\mathrm{Cu}_{6} \mathrm{Sn}_{5}\right.$ compound). Refinement of present large intermetallic particles in babbitts structure leads to increase of the service life of the sliding bearing. The paper studied the influence of severe plastic deformation by high pressure torsion on the microstructure and microhardness of cast babbit $\mathrm{Sn} 11 \mathrm{Sb} 5,5 \mathrm{Cu}$. Cast babbitt $\mathrm{Sn} 11 \mathrm{Sb} 5,5 \mathrm{Cu}$ is characterized by a microstructure with large cubic $\beta$-phase particles SnSb with a size of $100-200 \mathrm{~mm}$, small $\eta$-phase in the form of large needles $\mathrm{Cu}_{6} \mathrm{Sn}_{5}$ compound. The bulk $\alpha$-phase is submicrocrystalline with grain size of $1-3 \mathrm{~mm}$. The billets were subjected to high pressure torsion on Bridgman anvils at room temperature for 2, 5 and 10 turns, which corresponded to a true logarithmic degree of deformation 7,8 and 9 . After high pressure torsion with $e=7$, the refinement and spheroidizing of $\beta$-phase from an initial size to the 15-20 microns occur, a further increasing of the degree of deformation does not lead to a change in $\beta$-phase size. In the $\alpha$-phase grain refinement occurs when $e$ were 7 and 8 and grain size consist $1 \mathrm{~mm}$, when $e=9$ grain size was about $200 \mathrm{~nm}$. Microhardness measurements revealed that high pressure torsion with $e=9$ increased the microhardness of babbit Sn11Sb5,5Cu by $80 \%$.

Keywords: babbit, severe plastic deformation, high pressure torsion, microstructure.

\section{Структура и свойства баббита Б83 подвергнутого кручению под квазигидростатическим давлением}

\author{
Валеев И.Ш. ${ }^{\dagger}$ Валеева А.Х., Мулюков Р.Р., Хисамов Р.Х. \\ ${ }^{\dagger}$ valeevs@mail.ru \\ Институт проблем сверхпластичности металлов РАН, ул. Халтурина 39, 450001, Уфа, Россия
}

В качестве материала для вкладышей подшипников скольжения многих крупногабаритных агрегатов (например, турбин гидроэлектростанций), традиционно используются сплавы Баббита. Структура высокооловянистого баббита Б83 состоит из трех фаз: $\alpha$-фазы, являющейся твердым раствором сурьмы и меди в олове, $\beta$-фазы, представляющей собой кристаллы $\mathrm{SnSb}$ с гексагональной и ромбоэдрической решеткой и мелкой $\eta$-фазы $\left(\mathrm{Cu}_{6} \mathrm{Sn}_{5}\right)$. Измельчение крупных интерметаллидных частиц, присутствующих в структуре баббитов приводит к повышению усталостной прочности и способствует увеличению ресурса работы подшипников скольжения. В работе проведено исследование влияния интенсивной пластической деформации, реализуемой методом кручения под квазигидростатическим давлением, на микроструктуру и микротвердость литого баббита Б83. Литой баббит Б83 (Sn11Sb5,5Cu) характеризуется микроструктурой с крупными кубическими частицами $\beta$-фазы SnSb размером $100-200$ мкм, мелкой $\eta$-фазой в виде крупных игл соединения $\mathrm{Cu}_{6} \mathrm{Sn}_{5}$. При этом основная $\alpha$-фаза является субмикрокрис-таллической с размером зерен 1 - 3 мкм. Заготовки толщиной 0,5 мм и диаметром 10 мм подвергали кручению под высоким давлением на наковальнях Бриджмена при комнатной температуре на 2, 5 и 10 оборотов, что соответствовало истинной логарифмической степени деформации 7, 8 и 9. После ИПД методом ККГД с $e=7$ наблюдается измельчение и сфероидизация частиц $\beta$-фазы с исходного размера до 15-20 мкм, дальнейшее увеличение степени деформации не приводит к изменению размеров частиц $\beta$-фазы. В $\alpha$-фазе происходит измельчение зерна при истинной логарифмической степени деформации е равной 7 и 8 с исходного размера до 1 мкм, при $e=9$ размер зерна составляет около 200 нм. Измерения микротвердости показали, что ИПД методом ККГД со степенью $e=9$ приводит к повышению микротвердости баббита Б83 на $80 \%$.

Ключевые слова: баббит, интенсивная пластическая деформация, кручение под квазигидростатическим давлением, микроструктура. 


\section{1. Введение}

В качестве материала для вкладышей подшипников скольжения многих крупногабаритных агрегатов (например, турбин гидроэлектростанций), традиционно используются сплавы Баббита. Наиболее высокими трибологическими свойствами обладают баббиты на основе олова - 589, Б83 [1,2]. Структура высокооловянистого баббита Б83 состоит из трех фаз: $\alpha$-фазы, являющейся твердым раствором сурьмы и меди в олове, $\beta$-фазы, представляющей собой кристаллы SnSb c гексагональной и ромбоэдрической решеткой и мелкой $\eta$-фазы $\left(\mathrm{Cu}_{6} \mathrm{Sn}_{5}\right)$ [3]. Измельчение крупных интерметаллидных частиц, присутствующих в структуре баббитов приводит к повышению усталостной прочности и способствует увеличению ресурса работы подшипников скольжения [4-6]. Известно [7-9], что интенсивная пластическая деформация (ИПД), является эффективным способом создания в материале субмикрокристаллической и нанокристаллической структуры.

Изучение влияния равноканального углового прессования и поверхностной фрикционной обработки на микроструктуру и триботехнические характеристики баббита Б83 $[10,11]$ показали значительное влияние ИПД на параметры материала. Одним из наиболее эффективных методов формирования нано- и субмикрокристаллической структур, обладающих повышенной прочностью с сохранением достаточно высокого запаса пластичности считается интенсивная пластическая деформация кручением [7-9].

Данная работа посвящена исследованию влияния интенсивной пластической деформации, реализуемой методом кручения под квазигидростатическим давлением (КГД), на микроструктуру и микротвердость баббита Б83.

\section{2. Материалы и методики}

В качестве материала исследования выбран баббит Б83 $(11 \% \mathrm{Sb}, 5,5 \% \mathrm{Cu}$, остальное - Sn), полученный обычным литьем в кокиль.

Заготовки толщиной 0,5 мм и диаметром 10 мм вырезали из литого прутка на установке для электроискровой резки металла, а затем подвергали кручению под высоким давлением на наковальнях Бриджмена при комнатной температуре на 2, 5 и 10 оборотов. Степень деформации рассчитывали по формуле [12]:

$$
\varepsilon_{\text {истин }}=\ln \left[1+\left(\frac{2 \pi N r}{h}\right)^{2}\right]^{1 / 2}+\ln \frac{h_{0}}{h},
$$

где $N-$ число вращений, $h_{0}$ и $h$-начальная и конечная толщина диска, $r-$ радиус диска.

Конечная толщина дисков $-0,13$ мм, при этом значение истинной логарифмической степени деформации составляло 7, 8 и 9.

Для выявления структуры баббита образцы сначала подвергали механической полировке, затем - химическому травлению раствором азотной и уксусной кислоты в глицерине [13]. Микроструктуру исследовали на сканирующем электронном микроскопе PЭM «TESCAN
MIRA 3LMH» с полевым катодом и программным обеспечением CHANNEL 5.

Чтобы получить более полное представление о микроструктурных изменениях измеряли микротвердость центральной части образцов по Виккерсу на на оптическом микроскопе Axiovert-100A, используя приставку «МНТ-10», при нагрузке индентора 1,0 Н. Для каждого состояния проводили не менее десяти измерений, при этом коэффициент вариации измерений не превышал $5 \%$.

\section{3. Результаты и обсуждение}

На рис. 1 приведена электронная микрофотография структуры баббита в исходном литом состоянии. Литой баббит характеризуется микроструктурой с крупными кубическими частицами $\beta$-фазы $\mathrm{SnSb}$ размером $100-200$ мкм, мелкой $\eta$-фазой в виде крупных игл соединения $\mathrm{Cu}_{6} \mathrm{Sn}_{5}$. При этом основная $\alpha$-фаза является субмикрокристаллической с размером зерен $1-3$ мкм.

На рис. 2 приведены электронные микрофотографии структуры баббита Б83 после ИПД с различной степенью деформации. Из рисунков видно, что в структуре присутствуют темные выделения интерметаллидной $\beta$-фазы, окруженные матрицей.

После ИПД методом кручения под КГД с $e=7$ наблюдается измельчение и сфероидизация частиц $\beta$-фазы с исходного размера до 15-20 мкм (рис. 2a,b), дальнейшее увеличение степени деформации не приводит к изменению размеров частиц $\beta$-фазы (рис. 2c). Кроме того, видно, что интенсивная пластическая деформация вносит в структуру $\beta$-фазы баббита многочисленные дефекты (микротрещины). Также можно заметить, что происходит полное разрушение игольчатых частиц $\eta$-фазы и равномерное их распределение в матричной фазе.

На рис. 3 приведены фотографии микроструктуры $\alpha$-фазы баббита Б83 после кручения под высоким давлением. Видно, что в $\alpha$-фазе происходит измельчение зерна при истинной логарифмической степени деформации $e$ равной 7 и 8 с исходного размера до 1 мкм (рис. 3a,b), при $e=9$ размер зерна составляет около 200 нм (рис. 3c).

На рис. 4 приведена зависимость микротвердости баббита Б83 от истинной логарифмической степени деформации при кручении под высоким давлением. Видно, что ИПД методом кручения под КГД со степенью $e=9$ приводит к повышению микротвердости баббита Б83 на $80 \%$ (рис. 4 ).

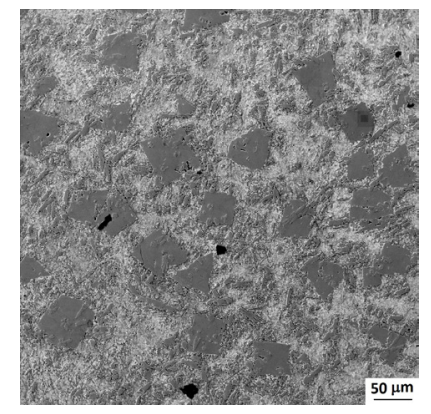

Рис. 1. Микроструктура баббита Б83 в литом состоянии. Fig. 1. Babbitt B83 microstructure in the cast state. 


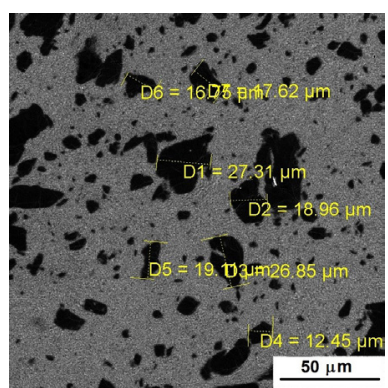

a

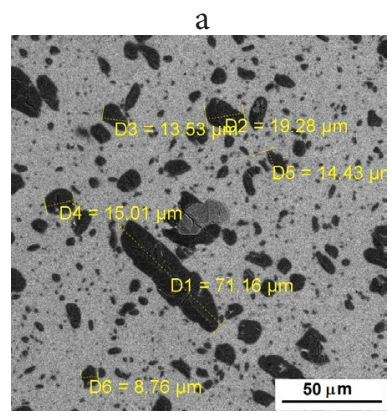

C
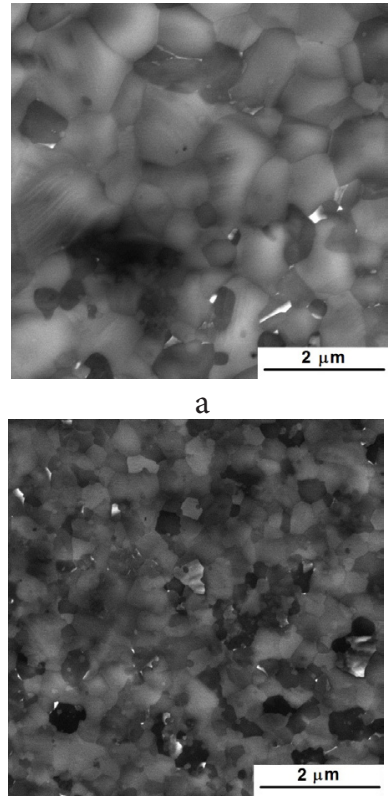

C

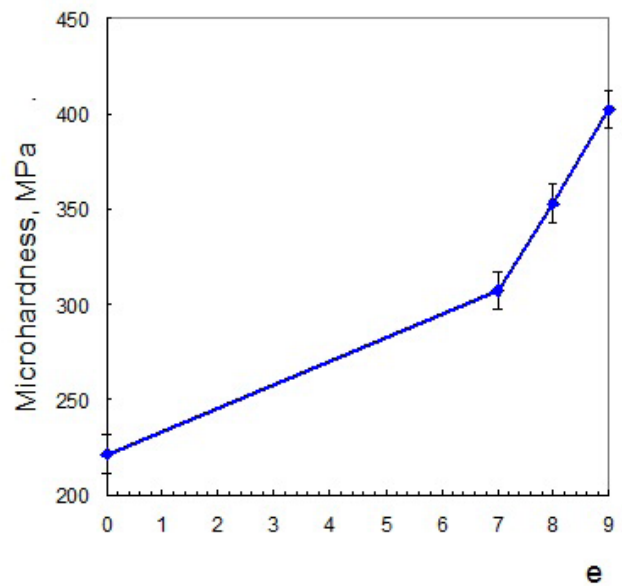

Рис. 4. Микротвердость баббита Б83 после КГД.

Fig. 4. Microhardness of babbit Sn11Sb5,5Cu after HPT.

\section{4. Выводы}

Показано, что интенсивная пластическая деформация методом кручения под квазигидростатическим давлением приводит к образованию субмикрокристаллической структуры в матричной $\alpha$-фазе баббита Б83, а также к значительному измельчению и сфероидизации $\beta$-фазы, что сопровождается значительным повышением микротвердости.

\section{Литература/References}

1. A. I. Shpagin. Antifrictional alloys. M.: Metallurgya (1956) 326 p. (in Russian) [А.И. Шпагин. Антифрикционные сплавы. М.: Металлургия (1956) 326 с.]

2. Wear-resistant materials in chemical machine building. Handbook. Ed. Yu. M. Vinogradov. L.: Mashinostroyenie (1977) 256 p. (in Russian) [Износостойкие материалы в химическом машиностроении. Справочник. Под ред. Ю.М. Виноградова. Л.: Машиностроение (1977) 256 c.]

3. F. A. Sadykov, N. P. Barykin, I. Sh. Valeev, V. N. Danilenko. Journal of Materials Engineering and Performance. 12, $29-36$ (2003).

4. I.M. Lyubarskii, L.S. Palatnik. Metallofizika of friction. M.: Metallurgy (1976) 176 p. (in Russian) [И.М. Любарский, Л.С. Палатник. Металлофизика трения. М.: Металлургия (1976) 176 с.]

5. F.A. Sadykov, N.P. Barykin, I.Sh. Valeev. Strength of Materials 34, 196-199 (2002).

6. N.P. Barykin, R.F. Fazlyahmetov, A. Kh. Valeeva. Metal science and Heat Treatment. 48, 88 - 91 (2006).

7. N.I. Noskova, R.R. Muluykov. Submicrocrystalline and nanocrystalline metalls and alloys. Urals Branch of the Russian Academy of Sciences, Ekaterinburg (2003) 279 p. (in Russian). [Н.И. Носкова, Р.Р. Мулюков. Субмикрокристаллические и нанокристаллические металлы и сплавы. Уральское отделение РАН. Екатеринбург (2003) 279 с.

8. A.P. Zhilyaev, A.I. Pshenichnyuk. Superplasticity and grain boundaries in ultrafine materials. M.: FIZMATLIT. (2008) 320 p. (in Russian) [А.П. Жиляев, А.И. Пшеничнюк. Сверхпластичность и границы зерен в ультрамелкозернистых материалах. М.: ФИЗМАТЛИТ. (2008) 320 с.]

9. A. P. Zhilyaev, T. G. Langdon. Prog. Mater. Sci. 53, 893 (2008).

10. L.G. Korshunov, N.I. Noskova, A.V. Korznikov, N. L. Chernenko, N. F. Vil'danova. The Physics of Metals and Metallography. 108, 519-526 (2009).

11. N. I. Noskova, L. G. Korshunov, A. V. Korznikov. Metal Science and Heat Treatment. 50, 593 - 599 (2008).

12. B. M. Efros, V. P. Pilyugin, A. M. Patselov, Y. Y. Beigelzimer, N.B. Efros. Ultrafine Grained Materials II (Y.T. Zhu, T. G. Langdon, R.S. Mishra, S.L. Semiatin, M. J. Saran, T. C. Lowe, eds.). Warrendale, PA: The Minerals, Metals and Materials Society. 193 - 197 (2002).

13. V.S. Kovalenko. Metallurgical reagents. M.: Metallurgya (1981) 120 p. (in Russian) [В.C. Коваленко.
[B. Металлографические реактивы. М.:Металлургия (1981) 120 c.] 